\title{
Endovascular Management of a Post-Traumatic Complex Arterioportal Fistula
}

\author{
Ankaj Khosla, Ben White, Sanjeeva Kalva and Anil Pillai* \\ Department of Radiology, University of Texas Southwestern Medical School, Dallas, USA
}

\begin{abstract}
In the present case report, we report the use of coils and n-butyl cyanoacrylate in the treatment of posttraumatic complex arterioportal fistula. This fistula resulted in ongoing hemodynamically significant gastrointestinal bleeding. Initially, coil embolization was used to treat the large feeding arteries of the AV fistula, but with subsequent discovery of multiple small feeding arteries, n-butyl cyanoacrylate was used for successful occlusion with preserved parenchymal perfusion.
\end{abstract}

Keywords: Arterioportal fistula; Hypertension; Obesity; Renal failure

\section{Case Presentation}

A 22-year-old male with a history of hypertension, obesity, and prior renal transplant presented to our institution with gunshot injuries to his abdomen. He underwent multiple open surgical procedures to remove the shrapnel and treat visceral organ injuries. His hospital course was complicated by renal failure requiring hemodialysis, severe intra-abdominal adhesions resulting in a frozen abdomen, persistent intra-abdominal infections and recurrent enteroatmospheric fistulae despite surgical revisions and loss of abdominal fascia preventing abdominal wound closure. These were treated using total parental nutrition and complex and intensive wound care using an ostomy apparatus and abdominal wound vac. Several months into his hospital course, he was noted to have blood within the ostomy bag and a persistent decrease in his hematocrit. The patient underwent endoscopy and additional exploratory surgery, but no clear source of bleeding was found. The patient had persistent bleeding that was minimally responsive to blood transfusions.

A contrast enhanced CT scan demonstrated fistulous connections between the hepatic arterial system and the portal venous system, a new finding from prior scans (Figure 1). A hepatic arteriogram demonstrated two large high flow arterio-portal fistulae supplied by the right hepatic artery (Figure 2). After selective catheterization of the feeding arteries with a microcatheter (Progreat, Terumo Tokyo, Japan), multiple detachable microcoils (Axiom, EV3 Irvine, USA) were deployed to completely occlude the arteriovenous communications. A post-embolization angiogram revealed successful occlusion of the treated fistulae but persistent arterio-portal shunting through multiple, but previously unidentified, small arteries feeding the portal vein through multiple small fistulous communications (Figure 3). Given the presence of multiple fistulous small communications, we decided to treat it like an arteriovenous malformation.

Two weeks later, the patient returned to the angiography suite. Repeat celiac angiogram confirmed the previously identified findings of persistent arterio-portal communications from multiple small arterioles (Figure 4). A microcatheter (Progreat, Terumo, Tokyo, Japan) was advanced through the feeding vessels as close to the arterioportal communications as possible and embolization was performed with n-butyl cyanoacrylate (n-BCA), mixed with iodized oil (Lipiodol; Guerbet, Aulnay-sous-Bois, France) at a ratio of 1:4. A total of $5.5 \mathrm{~mL}$ of nBCA-iodized oil was injected. At the end of the procedure, there was significant reduction of flow through the fistulae and minimal opacification of the portal vein. Clinically, the patient's bleeding decreased, but he remained transfusion dependent.

After four weeks, the patient was brought back to the angiographic suite for a repeat procedure. The celiac axis angiogram re-demonstrated multiple small feeding arteries feeding the right hepatic arterioportal communications outside of those treated previously. These branches predominantly arose from the cystic artery and the portions of the right hepatic artery supplying segments 7 and 8 . Each of these arteries was selected with a microcatheter and embolized using nBCA mixed with lipiodol at a ratio of 1:4. A total of $6 \mathrm{~mL}$ of $\mathrm{nBCA}$-lipiodol solution was used. A post-embolization angiogram demonstrated minimal persistent arterioportal shunting (Figure 5).

After the embolization, the patient's bleeding decreased. Four months after the last embolization procedure, the patient continued to experience wound bleeding requiring transfusion. Surgical closure of

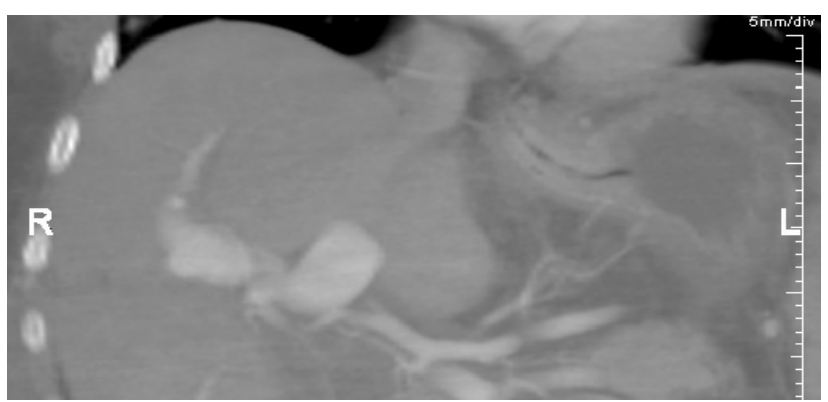

Figure 1: Coronal MPR CECT demonstrating opacification of the portal vein consistent with a large right arterioportal fistula.

${ }^{*}$ Corresponding author: Anil Pillai, Department of Radiology, University of Texas Southwestern Medical School, Dallas, TX- 75390, USA, Tel: 75390-8548; E-mail: Anil.pillai@UTsouthwestern.edu

Received March 19, 2015; Accepted April 02, 2015; Published April 04, 2015

Citation: Khosla A, White B, Kalva S, Pillai A (2015) Endovascular Management of a Post-Traumatic Complex Arterioportal Fistula. J Vasc Med Surg 3: 198 doi:10.4172/2329-6925.1000198

Copyright: $\odot 2015$ Khosla A, et al. This is an open-access article distributed unde the terms of the Creative Commons Attribution License, which permits unrestricted use, distribution, and reproduction in any medium, provided the original author and source are credited. 
Citation: Khosla A, White B, Kalva S, Pillai A (2015) Endovascular Management of a Post-Traumatic Complex Arterioportal Fistula. J Vasc Med Surg 3: 198. doi:10.4172/2329-6925.1000198

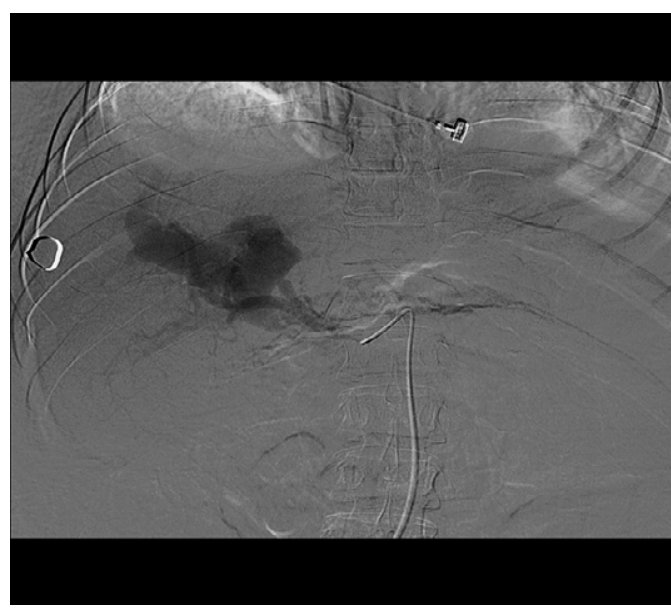

Figure 2: DSA celiac angiogram redemonstrating large right-sided arterioportal fistula.

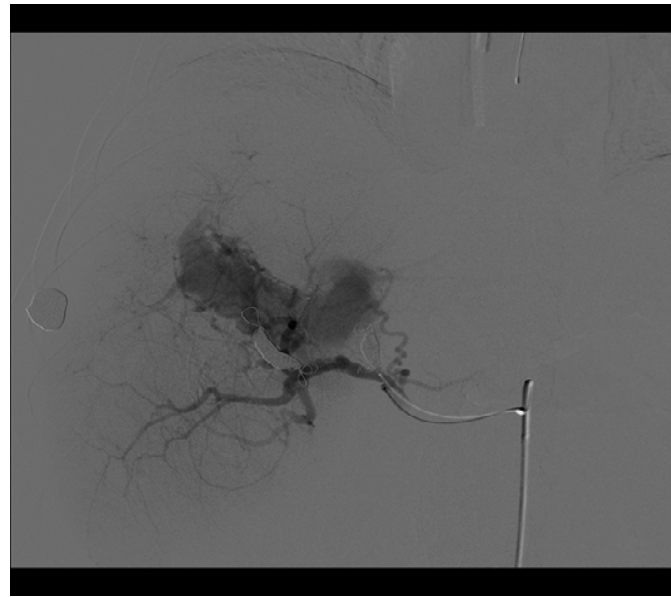

Figure 3: Post coil embolization DSA celiac angiogram-persistent filling of the fistula through small nidi.

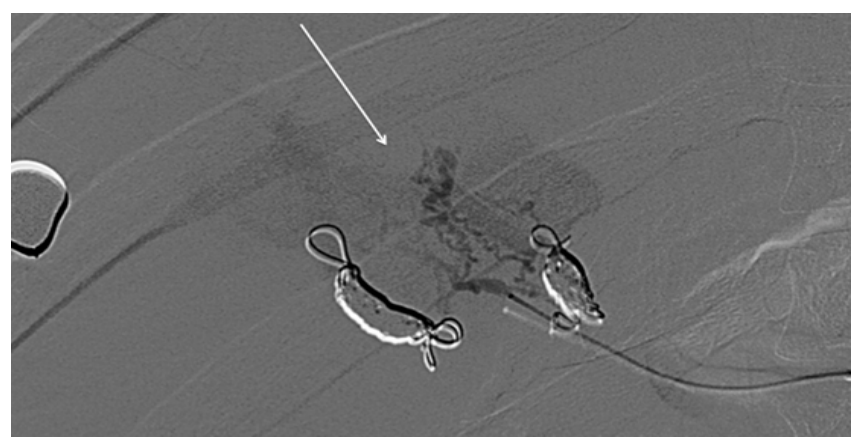

Figure 4: DSA arterial angiogram post coiling demonstrates with nidus (white arrow) and associated portal vein filling.

the open wounds was planned. Interventional radiology was consulted to evaluate for a recurrent arterioportal communication as a potential cause of bleeding and to consider portal decompression via a TIPS shunt placement to reduce surgical blood loss. Hemodynamic evaluation through free and wedged hepatic venous pressure measurements revealed a normal portosystemic gradient. A celiac angiogram revealed complete occlusion of all the fistulous communications without portal vein opacification (portal vein was patent on portal venous phase of the celiac arteriogram) (Figure 6).

The patient underwent successful primary wound closure with minimal blood loss. There were no delayed sequelae of arterioportal fistulae, such as portal hypertension, bowel edema, or hepatic failure. $\mathrm{He}$ is currently undergoing continued abdominal wound care with plans for skin grafting in the future.

\section{Discussion}

Arterioportal fistulae and malformations are uncommon entities [1]. Most often, intrahepatic arterioportal fistulae occur secondary to direct liver trauma or with malignancy [2-8]. Associated complications include portal hypertension, distal embolization (pulmonary), and congestive heart failure [1,9]. A second etiology of arterioportal fistulae in pediatric populations is arterioportal fistula syndrome, a congenital disorder where multiple arterioportal fistulae develop in the absence

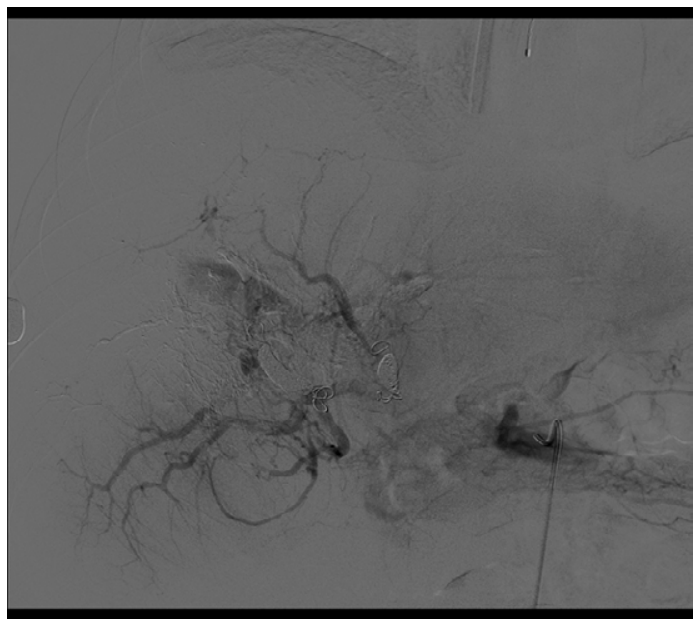

Figure 5: DSA post $2^{\text {nd }} n B C A$ glue embolization showing near complete obliteration of the shunt with minimal portal vein opacification.

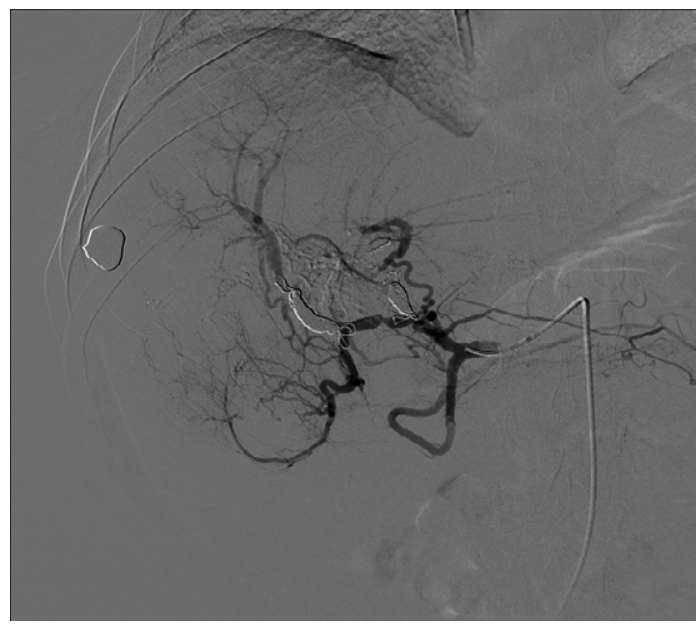

Figure 6: DSA celiac angiogram showing complete obliteration of the shunt post $\mathrm{nBCA}$ glue placement. 
of other arteriovenous abnormalities [3]. Arterioportal malformations are rare and most often are congenital in nature $[10,11]$. The limited literature suggests that these occur in isolation, with a possible association to conditions resulting in malformations in other locations such as hemorrhagic hereditary telegantecasia [12]. Regardless of etiology, similar complications result from both arteriportal fistulae and malformations.

Due to multiple life threatening associated complications, timely and effective treatment of arteriovenous fistulae/malformations is critical. Approaches to treatment have included both surgical and endovascular techniques. Endovascular treatments are preferred due to the rich vascular supply of the liver and the relative ease of treatment using this approach [1-3,5,13]. Most prior described endovascular therapies for these AV fistulas have described a coil-based approach $[2,3,6,9,13-19]$. This has also been the primary approach employed to treat vascular fistulas at other sites [20-22].

Arteriovenous malformations require a different form of treatment. The key differentiating factor between an arteriovenous malformation and fistula is the number of source arteries and the presence of a nidus. Fistulas have one or two relatively large feeding vessels that feed the shunt. Malformations are characterized by multiple smaller feeding vessels [23] which communicate with single/multiple draining veins through a nidus. While a fistula can easily be treated with coils deployed in the feeding artery, the mainstay for endovascular treatment of malformations is obliterating the nidus using liquid embolic materials such as ethylene vinyl alcohol copolymer (Onyx, Coviden, EV3, Plymouth, MN) or nBCA [24-27]. In fistulae, embolization with nBCA is used as a secondary technique, only if initial coil embolization is unsuccessful or fails. nBCA is avoided in many AV fistulae due to the difficulty in optimal positioning of the embolic material and the high risk of distal embolization [28]. In our literature search, we found only two cases where nBCA was used as the primary embolization method for post traumatic arteriorvenous fistulae, [29-31]. nBCA has been successfully employed in embolization of arteriovenous malformations in multiple other sites including the central nervous system, lungs, and extremities[32-34]. Limited data exists on treatment of arteriovenous malformations in the liver, and most interventions have occurred in pediatric populations $[35,36]$.

In our patient, coil embolization was attempted initially as he had large documented arterioportal fistulae. Post coiling, multiple feeding vessels from the right hepatic arterial system, which were not seen initially, continued to shunt through multiple small fistulous communications. For effective disruption of these communications, the majority or all of these communications would have to be occluded. Embolizing the right hepatic arterial system can result in multiple biliary complications including gallbladder infarction and intrahepatic biliary occlusion [37]. This is particularly a concern in transplant livers but can occur in healthy non-transplant livers as well. Limited reports have demonstrated the effective use of nBCA for embolotherapy of acute hepatic arterial hemorrhage in healthy livers $[4,38,39]$ and for treatment of arterioportal fistula $[9,30,31]$. As such, nBCA was felt to be a safer alternative, as it could be targeted primarily to the multiple small fistulous communications while maintaining relative hepatic artery patency.

The uniqueness of this case is that the patient developed complex small fistulous communications following embolization of large arterioportal fistulae. Though it is possible that these communications existed prior to embolization of large fistulae but were masked by high flow through the large fistulae, it is of authors' opinion that these small fistulous communications developed through collateralization of distal segments of the occluded hepatic artery branches. Such intrahepatic arterial collateralization is well known following embolization of hepatic arterial branches during planning of intra-arterial Yttrium-90 microsphere therapy (reference needed).

Portal hypertension is a relatively common complication of arterioportal fistula and can result in the development of varices, bowel edema, and hepatic failure. Most reports suggest treating the underlying cause before addressing the portal hypertension with a decompressive treatment such as TIPS [1,9]. As the patient had recurrence of bleeding post embolization, he was assessed for presence of portal hypertension. On repeat angiogram, no evidence of portal hypertension was found and shunt obliteration was confirmed. We postulate that the residual arterio-portal shunting that persisted after the $2^{\text {nd }}$ embolization eventually got occluded without any additional therapy secondary to slow flow in these fistulous communications. This delayed occlusion has been demonstrated following embolization of vascular malformations in other locations (particularly intracranial) [40-44].

\section{Conclusion}

In the present case report, we report the use of nBCA in the treatment of an acquired complex arterioportal fistula. This fistula was of traumatic etiology and resulted in ongoing hemodynamically significant bleeding. Initially, coil embolization was used to treat the large feeding arteries of a presumed simple AV fistula, but subsequent discovery of multiple small feeding arteries led an attempt of closure with a liquid embolic material that allowed successful occlusion with preserved parenchymal perfusion. The procedure was well tolerated without any complications or distal embolization.

\section{References}

1. Guzman E, McCahill L, Rogers F (2006) Arterioportal fistulas: introduction of a novel classification with therapeutic implications. Journal of Gastrointestinal Surgery 10: $543-550$

2. Redmond PL, Kumpe DA (1988) Embolization of an intrahepatic arterioporta fistula: case report and review of the literature. Cardiovasc Intervent Radiol 11: 274-277.

3. Lamireau T, Jean-François C, Philippe $P$, François $P$, Michel $P$, et al. (1999) Successful Embolization of Congenital Intrahepatic Arterioportal Fistula in Two Infants. Journal of Pediatric Gastroenterology and Nutrition 29: 211-214.

4. Koc O, Cil BE, Peynircioglu B, Emlik D, Ozbek O (2009) Complementary use of NBCA with the Amplatzer vascular plug for embolization of a high-flow traumatic hepatic arteriovenous fistula. Cardiovasc Intervent Radiol 32: 1105-1107.

5. lezzi R, Pedicelli A, Pirro F, Dattesi R, Agnes S, et al. (2011) Preliminary Experience Using N-butyl Cyanoacrylate for Management of Bleeding after Percutaneous Transhepatic Biliary Drain Placement: A Technical Note. CardioVascular and Interventional Radiology 34: 435-439.

6. Hirakawa M, Nishie A, Asayama Y, Ishigami K, Ushijima Y et al. (2013) Clinica outcomes of symptomatic arterioportal fistulas after transcatheter arterial embolization. World J Radiol 5: 33-40.

7. Itai Y, Furui S, Ohtomo K, Kokubo T, Yamauchi T, et al. (1986) Dynamic CT features of arterioportal shunts in hepatocellular carcinoma. AJR Am J Roentgenol 146: 723-727.

8. Kim TK, Choi BI, Han JK, Chung JW, Park JH, et al. (1998) Nontumorous arterioportal shunt mimicking hypervascular tumor in cirrhotic liver: two-phase spiral CT findings. Radiology 208: 597-603.

9. Yamagami T, Nakamura T, Nishimura T (2000) Portal Hypertension Secondary to Spontaneous Arterio-Portal Venous Fistulas: Transcatheter Arterial Embolization with n-Butyl Cyanoacrylate and Microcoils. Cardiovascular and Interventional Radiology 23: 400-402.

10. Bodner G, Peer S, Karner M, Perkmann R, Neuhauser B, et al. (2002) 
Citation: Khosla A, White B, Kalva S, Pillai A (2015) Endovascular Management of a Post-Traumatic Complex Arterioportal Fistula. J Vasc Med Surg 3: 198. doi:10.4172/2329-6925.1000198

Page 4 of 4

Nontumorous vascular malformations in the liver: color Doppler ultrasonographic findings. J Ultrasound Med 21: 187-197.

11. Chae EJ, Goo HW, Kim SC, Yoon CH (2004) Congenital intrahepatic arterioportal and portosystemic venous fistulae with jejunal arteriovenous malformation depicted on multislice spiral CT. Pediatric Radiology 34: 428-431.

12. Hashimoto M, Tate E, Nishii T, Watarai J, Shioya T, et al. (2003) Angiography of Hepatic Vascular Malformations Associated with Hereditary Hemorrhagic Telangiectasia. CardioVascular and Interventional Radiology 26: 177-180.

13. Dwivedi AJ, Greben C, Krishnasastry KV (2006) Catheter embolization of an hepatic artery aneurysm: a case report. Vasc Endovascular Surg 40: 79-83.

14. Tasar M, Gulec B, Bozlar U, Saglam M, Ugurel MS, et al. (2005) Intrahepatic arterioportal fistula and its treatment with detachable balloon and transcatheter embolization with coils and microspheres. Clin Imaging 29: 325-330.

15. Maes J, D'Archambeau O, Snoeckx A, Op de Beeck B, Voormolen M, et al (2010) Post-traumatic hepatic arterial pseudoaneurysm and arterioportal shunt. JBR-BTR 93: 189-192.

16. Flum AS, Geiger JD, Gemmete JJ, Williams DM, Teitelbaum DH, et al. (2009) Management of a traumatic hepatic artery pseudoaneurysm and arterioportal fistula with a combination of a stent graft and coil embolization using flow control with balloon remodeling. Journal of Pediatric Surgery 44: e31-e36.

17. Bapuraj JR, Kalra N, Rao KL, Suri S, Khandelwal N (2001) Transcatheter coi embolization of a traumatic intrahepatic arterioportal fistula. Indian $\mathrm{J}$ Pediatr 68: 673-676.

18. English WP, Johnson MB, Borman KR, Turner WW Jr (2001) Mesenteric ischemia: an unusual presentation of traumatic intrahepatic arterioportal fistula. Am Surg 67: 865-867.

19. Lerut J, Vauthey N, Triller J, Gertsch P, Schweizer W (1992) Intrahepatic arterioportal fistula following conservative treatment of a traumatic liver rupture: case report. J Trauma 33: 760-764.

20. Cekirge S, Oguzkurt L, Saatçi I, Boyvat F, Balkanci F (1996) Embolization of a high-output postnephrectomy aortocaval fistula with Gianturco coils and cyanoacrylate. Cardiovasc Intervent Radiol 19: 56-58.

21. Krings T, Chng SM, Ozanne A, Alvarez H, Rodesch G, et al. (2005) Hereditary hemorrhagic telangiectasia in children: endovascular treatment of neurovascular malformations. Neuroradiology 47: 946-954.

22. Yamakado K, Nakatsuka A, Tanaka N, Takano K, Matsumura K, et al. (2000) Transcatheter Arterial Embolization of Ruptured Pseudoaneurysms with Coils and n-Butyl Cyanoacrylate. Journal of Vascular and Interventional Radiology 11: $66-72$.

23. Koenig E, Thron A, Schrader V, Dichgans J (1989) Spinal arteriovenous malformations and fistulae: clinical, neuroradiological and neurophysiological findings. J Neurol 236: 260-266.

24. Hillman J (2001) Population-based analysis of arteriovenous malformation treatment. J Neurosurg 95: 633-637.

25. Dubois J, Garel L (1999) Imaging and therapeutic approach of hemangiomas and vascular malformations in the pediatric age group. Pediatr Radiol 29: 879893

26. Jahan R, Murayama Y, Gobin YP, Duckwiler GR, Vinters HV, et al. (2001) Embolization of arteriovenous malformations with Onyx: clinicopathological experience in 23 patients. Neurosurgery 48: 984-995.

27. Han MH, Seong SO, Kim HD, Chang KH, Yeon KM, et al. (1999) Craniofacia Arteriovenous Malformation: Preoperative Embolization with Direct Puncture and Injection of n-Butyl Cyanoacrylate. Radiology 211: 661-666.

28. Kumar A, Ahuja CK, Vyas S, Kalra N, Khandelwal N, et al. (2012) Hepatic arteriovenous fistulae: role of interventional radiology. Dig Dis Sci 57: 2703 2712.

29. Yamagami T, Nakamura T, Nishimura T (2000) Portal hypertension secondary to spontaneous arterio-portal venous fistulas: transcatheter arterial embolization with n-butyl cyanoacrylate and microcoils. Cardiovasc Intervent Radiol 23: 400-402.

30. Sonomura T, Kawai N, Kishi K, Ikoma A, Sanda H, et al. (2014) N-Butyl Cyanoacrylate Embolization with Blood Flow Control of an Arterioportal Shun That Developed after Radiofrequency Ablation of Hepatocellular Carcinoma. Korean J Radiol 15: 250-253.

31. Cil BE (2004) Transhepatic embolization of a recanalized congenital hepatic arterioportal fistula with NBCA and coils. Cardiovasc Intervent Radiol 27: 172174

32. Benndorf G, Campi A, Hell B, Hölzle F, Lund J, et al. (2001) Endovascular management of a bleeding mandibular arteriovenous malformation by transfemoral venous embolization with NBCA. AJNR Am J Neuroradiol 22 359-362.

33. Lee BB, Bergan JJ (2002) Advanced management of congenital vascular malformations: a multidisciplinary approach. Cardiovasc Surg 10: 523-533.

34. Brown JW, Ruzmetov M, Vijay P, Rodefeld MD, Turrentine MW (2005) Pulmonary arteriovenous malformations in children after the Kawashima operation. Ann Thorac Surg 80: 1592-1596.

35. Fishman SJ, Burrows PE, Leichtner AM, Mulliken JB et al. (1998) Gastrointestinal manifestations of vascular anomalies in childhood: Varied etiologies require multiple therapeutic modalities. Journal of pediatric surgery 33: $1163-1167$.

36. Caselitz M, Wagner S, Chavan A, Gebel M, Bleck JS, et al. (1998) Clinica outcome of transfemoral embolisation in patients with arteriovenous malformations of the liver in hereditary haemorrhagic telangiectasia (WeberRendu-Osler disease). Gut 42: 123-126.

37. Huang XQ, Huang ZQ, Duan WD, Zhou NX, Feng YQ (2002) Severe biliary complications after hepatic artery embolization. World J Gastroenterol 8: 119123.

38. Kish JW, Katz MD, Marx MV, Harrell DS, Hanks SE (2004) N-butyl cyanoacrylate embolization for control of acute arterial hemorrhage. J Vasc Interv Radiol 15 689-695.

39. Cagli B, Tuncel SA, Sengul E, Temizoz O, Unlu E, et al. (2011) Hemobilia and occult cystic artery stump bleeding after a laparoscopic cholecystectomy: endovascular treatment with N-butyl cyanoacrylate. Prague Med Rep 112: 132 136

40. Kao ST, Walker PW, Ferguson HW (2014) Posttraumatic arteriovenous malformation of the face: a case report. J Emerg Med 46: e5-8.

41. Mahmoud M, Allinson KR, Zhai Z, Oakenfull R, Ghandi $P$, et al. (2010) Pathogenesis of arteriovenous malformations in the absence of endoglin. Circ Res 106: 1425-1433.

42. Sasaki T, Hoya K, Kinone K, Kirino T, et al. (1995) Postsurgical development of dural arteriovenous malformations after transpetrosal and transtentorial operations: case report. Neurosurgery 37: 824-825.

43. Kutlu R, A Soylu (2009) Deep dorsal vein embolization with N-butyl-2 cyanoacrylate and lipiodol mixture in venogenic erectile dysfunction: early and late results. Radiol Oncol 43: 17-25

44. Duckwiler GR, Dion JE, Viñuela F, Reichman A (1992) Delayed venous occlusion following embolotherapy of vascular malformations in the brain. AJNR Am J Neuroradiol 13: 1571-1579. 